\title{
Comparison of three strategies for myocardial protection during coronary artery bypass graft surgery based on markers of cardiac damage
}

\author{
Alessandra Barassi ${ }^{\mathrm{a}, *}$, Giampaolo Merlini ${ }^{\mathrm{b}}$, Sergio Finazzi ${ }^{\mathrm{c}}$, Francesco Pallotti ${ }^{\mathrm{a}}$, \\ Vittorio Mantovani ${ }^{\mathrm{d}}$, Andrea Sala ${ }^{\mathrm{d}}$, Gianvico Melzi d'Eril ${ }^{\mathrm{a}}$ \\ a Dipartimento di Scienze Biomediche Sperimentali e Cliniche, Università degli Studi dell'Insubria, RAISE, Varese, Italy \\ ${ }^{\mathrm{b}}$ Laboratori di Biotecnologie, IRCCS Policlinico S. Matteo, Dipartimento di Biochimica, Università degli Studi di Pavia, Pavia, Italy \\ ${ }^{\mathrm{c}}$ Laboratorio di Analisi, Ospedale di Legnano, Legnano, Italy \\ ${ }^{\mathrm{d}}$ Divisione di Cardiochirurgia, Ospedale di Circolo, Varese, Italy
}

Received 3 September 2004; received in revised form 9 February 2005; accepted 10 March 2005

Available online 16 April 2005

\begin{abstract}
Objectives: To evaluate myocardial damage during coronary artery bypass grafting using three different intermittent cardioplegia and then measuring cTnI and CKMBm release.

Design and methods: Forty-two patients belonging to the hypothermic crystalloid $(n=16)$, hypothermic $(n=13)$, and normothermic blood $(n=13)$ groups were collected when removing the aortic cross-clamp $(t=0)$ and after $4,12,24$ and 48 h. For each patient, cumulative $\mathrm{cTnI}$ and CKMBm release was calculated as the five measurement mean. There were no significant preoperative and operative differences in the three groups.

Results: In the normothermic group, cTnI mean values at 4, 12, and $24 \mathrm{~h}$ were significantly lower than those in both hypothermic groups; moreover, CKMBm mean values were higher at 4, 12, and $24 \mathrm{~h}$ in the hypothermic crystalloid group and at 4 and $12 \mathrm{~h}$ in the hypothermic blood group than in the normothermic group. In the normothermic group, the area under the curve of the release of both markers was significantly lower than in the hypothermic groups. No significant difference was reported in the release of both markers in hypothermic groups.
\end{abstract}

Conclusions: A strategy of normothermic cardioplegia seems to preserve myocardium better than hypothermic cardioplegia. (C) 2005 The Canadian Society of Clinical Chemists. All rights reserved.

Keywords: Myocardial protection; Troponin I; Creatine kinase-MB mass; Cardioplegic solution; Cardiopulmonary bypass

\section{Introduction}

Blood cardioplegia [1] is a consolidated technique for myocardial protection during cardiac operations, with its validity confirmed by several clinical trials [2]. Many controversial opinions still abound regarding the question as to whether cold, tepid or warm, antegrade or retrograde, intermittent or continuous, and crystalloid or blood cardioplegia are preferable. Hypothermia has been routinely used

\footnotetext{
* Corresponding author.

E-mail address: alessandra.barassi@tin.it (A. Barassi).
}

as it reduces oxygen demand by decreasing the basal metabolic rate. However, hypothermia may have adverse effects like "cold contracture" of microcirculation in coronary arteries to cause additional ischemia and reperfusion injury [3], inhibiting the sodium pump to cause edema, and shifting the oxygen-hemoglobin dissociation curve leftward [4]. It is not surprising, therefore, that the optimal temperature of cardioplegia remains controversial [5]. Continuous blood cardioplegia has been widely advocated as a more physiological approach, but perfusion is often interrupted to allow adequate visualization of the operative field [5]. For this reason, intermittent delivery has been proposed as an equally effective and more practical 
technique [6]. Many surgeons believe that blood cardioplegia is superior to crystalloid, but benefits appear to be only of marginal clinical consequence [7] or may not be present at all $[8,9]$.

The aim of this study was to compare the degree of myocardial protective effect during coronary artery bypass grafting (CABG) using three different intermittent cardioplegia: hypothermic crystalloid [10], hypothermic blood [11], and normothermic blood [12]. To assess the damage of cardiac tissue, the concentrations of cTnI and CKMBm released postoperatively in peripheral blood were measured.

\section{Materials and methods}

This study was approved by the Human Research Ethics Committee of the institution and the involved patients gave their informed consent.

\section{Patients}

Forty-two patients (27 men, 15 women, mean age 65 years, range 50 to 78 ) were prospectively randomized to hypothermic crystalloid $(n=16)$, hypothermic blood $(n=$ $13)$, or normothermic blood $(n=13)$ intermittent cardioplegia. Preoperative and operative clinical parameters are shown in Table 1. All patients were affected by three-vessel coronary artery disease with normal left ventricle function and underwent isolated elective coronary artery bypass operation. Exclusion criteria were: previous cardiac surgery, recent myocardial infarction ( $<2$ months), diabetes mellitus, and renal failure.

Table 1

Preoperative and operative characteristics of the three groups of patients (median and range)

\begin{tabular}{llll}
\hline Variables & $\begin{array}{l}\text { Hypothermic } \\
\text { crystalloid }\end{array}$ & $\begin{array}{l}\text { Hypothermic } \\
\text { blood }\end{array}$ & $\begin{array}{l}\text { Normothermic } \\
\text { blood }\end{array}$ \\
\hline $\begin{array}{l}\text { Number of } \\
\text { patients }\end{array}$ & 16 & 13 & 13 \\
$\begin{array}{l}\text { Age (years) } \\
\text { Women/men }\end{array}$ & $67(51-73)$ & $64(50-78)$ & $66(53-75)$ \\
Height (cm) & $163(151-188)$ & $165(150-175)$ & $4 / 9$ \\
Weight (kg) & $75(58-95)$ & $74(62-102)$ & $73(58-95)$ \\
Graft number & 3 & 3 & 3 \\
Clamp time (min) & $62(43-80)$ & $65(45-81)$ & $63(37-79)$ \\
CPB ${ }^{\mathrm{a}}$ time (min) & $93(53-107)$ & $99(54-156)$ & $94(60-120)$ \\
LVEF ${ }^{\mathrm{b}}$ (\%) & $61(42-85)$ & $55(44-73)$ & $60(41-79)$ \\
Total amount of & 1649 & 1825 & 1710 \\
$\quad$ cardioplegic & $(650-2324)$ & $(590-2867)$ & $(625-2189)$ \\
$\quad$ solution, mL & & 4 & 4 \\
Patients & 5 & & \\
$\quad$ requiring & & & \\
$\quad$ ED ${ }^{\mathrm{c}}, n$ & & & \\
\hline
\end{tabular}

All the variables are not significantly $(P<0.05)$ different in the three groups.

${ }^{a}$ CPB: cardiopulmonary bypass.

b LVEF: left ventricle ejection fraction.

${ }^{c}$ ED: electrical defibrillation.
Surgery

All patients underwent standard elective coronary artery bypass operations through full-length median sternotomy, with cardiopulmonary bypass (CPB) and aortic cross-clamp. The routine procedures for CPB were followed with ascending aorta and right atrium cannulation and the venting was through the aortic root. The proximal vein graft anastomoses were performed after the distal ones under tangential aortic clamp. The left internal thoracic artery was used in all cases to bypass the left anterior descending coronary artery, while other coronary arteries received saphenous vein grafts.

\section{Cardioplegia}

\section{Intermittent hypothermic crystalloid}

St. Thomas cardioplegia was administered at a temperature of $4^{\circ} \mathrm{C}$. The induction dose before commencement of CPB consisted of a 3-min infusion in the aortic root at 150 $\mathrm{mL} / \mathrm{m}^{2} \mathrm{bsa} / \mathrm{min}$ (bsa: body surface area). The subsequent doses were administered every $20 \mathrm{~min}$ for a period of $2 \mathrm{~min}$ with the same infusion rate. The patients were cooled at $28^{\circ} \mathrm{C}$.

Intermittent hypothermic blood. Cold blood cardioplegia was administered at a temperature of $4^{\circ} \mathrm{C}$. The induction dose before commencement of CPB was $600 \mathrm{~mL}$ over $2 \mathrm{~min}$ with a potassium content of 18 to $20 \mathrm{mEq} / \mathrm{L}$. Every $20 \mathrm{~min}$, a maintenance dose of $400 \mathrm{~mL}$ over 2 min was administered. The potassium content of these subsequent doses was $10 \mathrm{mEq} / \mathrm{L}$. The patients were cooled at $28^{\circ} \mathrm{C}$.

Intermittent normothermic blood. The cardioplegia was similar to the cold blood group except for a temperature of $37^{\circ} \mathrm{C}$ for all doses. The patients were maintained at $37^{\circ} \mathrm{C}$ throughout the entire CPB period.

Perioperative myocardial infarction was diagnosed if the patient met at least one of the following criteria: (1) new $\mathrm{Q}$ waves $\geq 40 \mathrm{~ms}$ in two consecutive leads on at least two post-CABG ECGs; (2) new $\mathrm{R}$ waves $\geq 40 / 50 \mathrm{~ms}$ in $\mathrm{V}_{1} / \mathrm{V}_{2}$ on at least two post-CABG ECSs; (3) new, persistent, complete bundle-branch block compared to the pre-CABG ECG [13]. Enzyme criteria have been considered unreliable because of frequent unspecific elevation due to surgical tissue trauma, cardiopulmonary bypass, and transient ischemia during aortic cross-clamping [14].

\section{Laboratory assays}

Serum cTnI concentration was measured on a Dimension RxL analyzer (Dade Behring, Milano, Italy) using the second-generation assay. cTnI assay's detection limit was $<0.03 \mu \mathrm{g} / \mathrm{L}$; the assay range was $0-50 \mu \mathrm{g} / \mathrm{L}$ and the reference range was up to $0.07 \mu \mathrm{g} / \mathrm{L}$ (99th percentile). The total imprecision was $4 \%$ at a cTnI concentration of $0.344 \mu \mathrm{g} / \mathrm{L}$ 
and $3.5 \%$ at $3.29 \mu \mathrm{g} / \mathrm{L}$. Serum CKMBm concentration was measured with the same Dimension RxL. The minimum detectable concentration was $0.3 \mu \mathrm{g} / \mathrm{L}$. CKMBm assay's range was $0-150 \mu \mathrm{g} / \mathrm{L}$ and the lower and upper limits of the reference range were $0.6-3.5 \mu \mathrm{g} / \mathrm{L}$ (central, 95th percentile). The total imprecision was $4 \%$ at a CKMBm concentration of $3.7 \mu \mathrm{g} / \mathrm{L}$ and $4.1 \%$ at $18.3 \mu \mathrm{g} / \mathrm{L}$.

\section{Statistical analysis}

Comparisons among the three groups were analyzed using the summary measures to calculate the area under the curve (AUC) of cTnI and CKMB release [15]. Once the summary measure was calculated for each patient, the AUC values were treated as raw data. The arithmetic means of the AUC values of the three groups were compared using a $t$ test and $P$ values $<0.05$ were considered statistically significant. Appendix A gives the method used for calculating the AUC.

\section{Results}

No significant preoperative and operative differences were present in the three groups (Table 1). There were no perioperative myocardial infarctions or in-hospital deaths. No differences were observed in groups with regard to postoperative incidences of renal, respiratory, and neurological complications. Fig. 1 shows the kinetics of the appearance of $\mathrm{cTnI}$ and CKMBm in the three groups, respectively. When aortic declamping $(t=0)$ was performed, no significant difference $(P>0.35)$ was found in the $\mathrm{cTnI}$ and $\mathrm{CKMBm}$ average values in each of the three groups considered.

In particular, in the three groups, the number of patients with $\mathrm{cTnI}$ or with $\mathrm{CKMBm}$ levels higher than the decision limit used in our laboratory for AMI $(0.18 \mu \mathrm{g} / \mathrm{L}$ for $\mathrm{cTnI}$ and $0.45 \mu \mathrm{g} / \mathrm{L}$ for CKMBm) was similar $(80 \%, 85 \%, 83 \%$ and $60 \%, 70 \%, 68 \%$, respectively). Following aortic declamping, the curves of cTnI and of CKMBm from hypothermic crystalloid and normothermic blood patients reached average peaks at $4 \mathrm{~h}$, respectively, while the curve from hypothermic blood patients reached a similar peak (at $4 \mathrm{~h}$ ) but instead of decreasing immediately, as was the case for the other two groups, it remained relatively stable for $20 \mathrm{~h}$ for cTnI and for $8 \mathrm{~h}$ for CKMBm. Finally, at $48 \mathrm{~h}$, the concentrations of cTnI remained higher than those at the declamping time in the case of the two hypothermic groups whereas the concentrations of CKMBm of the three groups were the same at declamping time. In the normothermic blood group, cTnI mean values at 4, 12, and $24 \mathrm{~h}$ were significantly lower than those in hypothermic crystalloid $(P=0.006, P=0.001, P=0.003$, respectively) and hypothermic blood $(P=0.05, P=0.016$, $P=0.001$, respectively) groups; moreover, CKMBm mean values in the normothermic blood group were also lower at 4, 12, and $24 \mathrm{~h}$ in comparison with the hypothermic
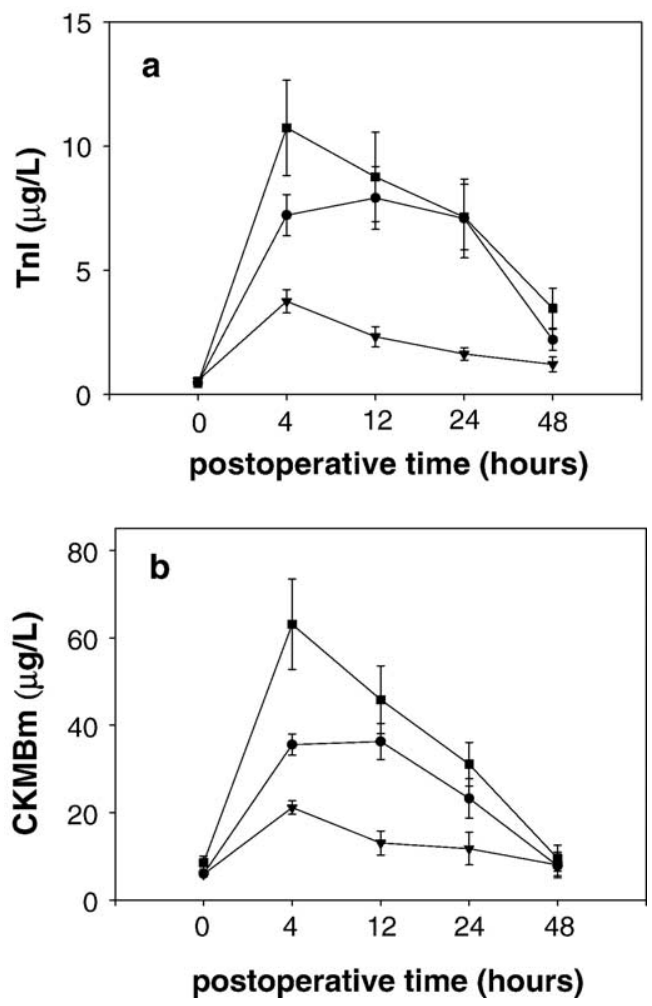

Fig. 1. Serum cTnI (a) and CKMBm (b) concentration at different time points after $\mathrm{CABG}$ surgery, using three different forms of myocardial protection. $t=0$, aortic declamping time. Values are expressed as mean \pm standard error. Intermittent cardioplegic solutions: hypothermic crystalloid $(\boldsymbol{\square})$, hypothermic blood $(\bullet)$, normothermic blood $(\boldsymbol{\nabla})$. cTnI levels of the normothermic blood group are lower $(P<0.05)$ than levels of both hypothermic groups at 4,12 , and $24 \mathrm{~h}$; CKMBm levels of the normothermic blood group are lower $(P<0.006)$ than levels of the hypothermic crystalloid group at 4,12 , and $24 \mathrm{~h}$ and lower $(P<0.007)$ than levels of the hypothermic blood group at 4 and $12 \mathrm{~h}$; cTnI and CKMBm levels in hypothermic groups are not significantly different at 4, 12, 24, and $48 \mathrm{~h}$.

crystalloid group $(P=0.003, P=0.003, P=0.006)$ and at 4 and $12 \mathrm{~h}$ in comparison with the hypothermic blood group $(P=0.005, P=0.007)$. The mean values of both markers in the hypothermic groups were not significantly different at $4,12,24$, and $48 \mathrm{~h}(P>0.35$ for cTnI and $P>0.26$ for $\mathrm{CKMBm}$ ).

Table 2 gives statistics of the AUC of cTnI and $\mathrm{CKMBm}$ release for comparing the three groups and the difference among the groups is expressed as the ratio of the arithmetic means. The arithmetic mean $( \pm$ SEM) of both $\mathrm{cTnI}$ and CKMBm AUCs in the three groups were $6.619( \pm 1.06) \mu \mathrm{g} / \mathrm{L}$ and $31.775( \pm 4.09) \mu \mathrm{g} / \mathrm{L}$ in the hypothermic crystalloid protocol, $5.615( \pm 0.63) \mu \mathrm{g} / \mathrm{L}$ and $23.161( \pm 2.77) \mu \mathrm{g} / \mathrm{L}$ in the hypothermic blood protocol, and $1.899( \pm 0.25) \mu \mathrm{g} / \mathrm{L}$ and $12.077( \pm 2.47) \mu \mathrm{g} / \mathrm{L}$ in the normothermic blood protocol, respectively. The AUC means of cTnI and CKMBm release in patients treated with the normothermic protocol resulted in significantly lower values than those of patients treated with the hypothermic crystalloid $(P<0.05)$ and with the hypo- 
Table 2

Statistical analysis of cTnI and CKMBm release during the first $48 \mathrm{~h}$ after CABG surgery using three different forms of myocardial protection.

\begin{tabular}{|c|c|c|c|}
\hline & $\begin{array}{l}\text { Hypothermic } \\
\text { crystalloid (a) }\end{array}$ & $\begin{array}{l}\text { Hypothermic } \\
\text { blood (b) }\end{array}$ & $\begin{array}{l}\text { Normothermic } \\
\text { blood (c) }\end{array}$ \\
\hline \multicolumn{4}{|l|}{$c T n I$} \\
\hline $\begin{array}{c}\text { AUC (arithmetic } \\
\text { mean, } \mu \mathrm{g} / \mathrm{L})\end{array}$ & 6.619 & 5.615 & 1.899 \\
\hline \multirow{2}{*}{$\begin{array}{l}95 \% \text { Confidence } \\
\text { interval }\end{array}$} & $4.55-8.71$ & $4.38-6.84$ & $1.40-2.38$ \\
\hline & (a) vs. (b) & (b) vs. (c) & (a) vs. (c) \\
\hline $\begin{array}{l}\text { Ratio of } \\
\text { arithmetic mean }\end{array}$ & 1.17 & 2.95 & 3.48 \\
\hline$t$ Test & $t=0.77$ & $t=5.50$ & $t=3.92$ \\
\hline ( $P$ value $)$ & $P>0.05$ & $P<0.001$ & $P<0.001$ \\
\hline \multicolumn{4}{|l|}{$C K M B m$} \\
\hline $\begin{array}{l}\text { AUC (arithmetic } \\
\text { mean, } \mu \mathrm{g} / \mathrm{L})\end{array}$ & 31.775 & 23.161 & 12.077 \\
\hline \multirow{2}{*}{$\begin{array}{l}95 \% \text { Confidence } \\
\text { interval }\end{array}$} & $23.12-39.16$ & $17.73-28.59$ & $7.23-16.91$ \\
\hline & (a) vs. (b) & (b) vs. (c) & (a) vs. (c) \\
\hline $\begin{array}{l}\text { Ratio of arithmetic } \\
\text { mean }\end{array}$ & 1.37 & 1.92 & 2.63 \\
\hline$t$ Test & $t=1.53$ & $t=2.98$ & $t=3.76$ \\
\hline$(P$ value $)$ & $P>0.05$ & $P<0.05$ & $P<0.001$ \\
\hline
\end{tabular}

AUC: area under the curve.

thermic blood $(P<0.05)$ protocol. No statistically significant difference resulted in the AUC means of cTnI or of CKMBm in the hypothermic groups $(P>0.05)$.

\section{Discussion}

Our results indicate that the use of a blood normothermic cardioplegic solution is more protective than hypothermic solutions (crystalloid or blood). The use of cardioplegic solution in cardiac surgery is necessary to protect the cardiac muscle during ischemic arrest [16]. The heightened sensitivity and specificity of cTnI and of CKMBm have rendered such markers ideal in revealing a cardiac injury following an ischemic insult of a different nature. In the present study, by using these simple biochemical markers, we were able to detect small differences in myocardial protection at a subclinical level that would have otherwise been impossible to ascertain.

The aim of our study was to compare three different strategies of myocardial protection on a homogeneous population undergoing the same kind of surgery. The patients studied were subdivided into three groups on the basis of the kind of cardioplegic solution used and were selected in such a way so as to eliminate the preanalytical variables in order to attenuate systematic errors. All patients in this study underwent the same anesthetic and operative procedure, $\mathrm{CABG}$ procedure, and intensive care unit management. The clinical background of the three groups was almost identical: age, weight, height, cross-clamp time, $\mathrm{CPB}$ time, and left ventricle ejection fraction.
The homogeneity of the subjects and of the surgery typology is confirmed by the absence of statistically significant differences in the average values of the three groups $(P>0.35)$, both in cTnI as well as in CKMBm at the time of aortic declamping. The kinetics of release are different: in the case of hypothermic crystalloid and normothermic blood cardioplegia, both $\mathrm{cTnI}$ and $\mathrm{CKMBm}$ increase sharply and rapidly decrease after the peak at $4 \mathrm{~h}$ from aortic declamping. A similar kinetic of cTnI with a peak after $6 \mathrm{~h}$ was found by Giuliani et al. [17]. We have no explanation for the prolonged release of TnI $(20 \mathrm{~h})$ and CKMB ( $8 \mathrm{~h}) 4 \mathrm{~h}$ after cross-clamp only in the case of hypothermic blood cardioplegia.

Our data do not show a significant higher grade of myocardic protection exerted by hypothermic blood in comparison to hypothermic crystalloid cardioplegia. This finding does not support the hypothesis of a high protective effect of hypothermic blood putatively attributed to a better oxygenation through hemoglobin. The average raised concentration of ischemic markers in the hypothermic blood could refer to the lower availability of oxygen caused by displacement towards the left of the saturation curve of hemoglobin due to the lower temperature [18]. In vitro studies [19] have shown that at $20^{\circ} \mathrm{C}$, only $50 \%$ of the total oxygen content of blood cardioplegia is available to the tissue and this drops an additional 30\% when the temperature is lowered to $10^{\circ} \mathrm{C}$. Regarding the use of both hypothermic cardioplegia, a further cause of low myocardial protection could be due to intermittent administration; the oxygen supply would not, in fact, be adequate at a low temperature for the needs of the heart, forcing the cardiac muscle to derive energy only from glycolysis, a metabolic pathway insufficient to supply adequate energy [20].

Preservation of perioperative myocardial metabolism was demonstrated by Yau et al. [21] using normothermic blood cardioplegia. Warm cardioplegia maximized myocardial oxygen extraction and resulted in less lactate production compared with that seen with cold blood cardioplegia, implying relative preservation of aerobic metabolism. Mezzetti et al. have found that oxidative stress is completely prevented in hearts protected by warm blood cardioplegia compared with those protected by cold blood cardioplegia [22]. Utilizing a canine model of acute global myocardial ischemia followed by a cardioplegic arrest interval, Guyton's research group demonstrated that the warm blood technique, compared with both the cold blood and the cold crystalloid cardioplegia, led to a better systolic function, better overall left ventricular function, and better restoration of high energy phosphate levels [23].

Regarding these considerations, Liecthenstein has proposed the use of normothermic solutions via a continual flow [1,24] obtaining extremely encouraging results, of which one that is particularly notable is a significant reduction in perioperative myocardial infarction, a lower mortality rate in 30 successive days and better cardioprotection in patients with reduced cardiac reserve [25]. 
Overall, an important limitation in continued administration was of a surgical nature, because the visualization of the operative field was made difficult by the blood flow, as well as by the abundant volume of the cardioplegic solution [25]. To avoid this problem, the intermittent administration of normothermic blood cardioplegia was proposed [12].

Tian studied the effects of the solution administered at 10min intervals on pig hearts [26]. The results showed only reduced ischemic damage and between them, non-cumulative. The author concluded that the administration of a sanguineous normothermic solution could be interrupted for limited periods without causing myocardial injury. Our results confirm this hypothesis: the release of cTnI and CKMBm, indices of myocardial damage, are significantly lower in patients treated with normothermic cardioplegia than in those receiving cold solutions. Whether the higher release of cTnI and CKMBm in the cold groups might be predictive of an adverse clinical outcome in a larger patient population or in higher-risk patients remains to be investigated.

\section{Appendix A. Calculation of area under the curve [15]}

The area under the curve (AUC) was calculated by adding the areas under the graph between each pair of consecutive observations.

If we have $n+1$ measurements $y_{i}$ at times $(i=0, \ldots, n)$, then the AUC is calculated as:

$\mathrm{AUC}=1 / 2 \sum_{i=0}^{n-1}\left(t_{i+1}-t_{i}\right)\left(y_{i}+y_{i+1}\right)$

Example: consider the cTnI data for a hypothermic crystalloid cardioplegia patient. At time zero (aortic declamping), at 4, 12, 24, $48 \mathrm{~h}$, the cTnI concentrations were $0.3,11.4$, $8.0,6.3$, and $4.5 \mu \mathrm{g} / \mathrm{L}$, respectively. Thus, we have:

$$
\begin{aligned}
\mathrm{AUC}= & 4 \times(0.3+11.4) / 2+(12-4) \times(11.4+8.0) / 2 \\
& +(24-12) \times(8.0+6.3) / 2+(48-24) \\
& \times(6.3+4.5)=292.8 \mu \mathrm{g} \mathrm{h} / \mathrm{L}
\end{aligned}
$$

If we standardize by the length of the study, $48 \mathrm{~h}$, we get $292.8 / 48=6.1 \mu \mathrm{g} / \mathrm{L}$.

\section{References}

[1] Lichtenstein SV, Ashe KA, el Dalati H, Cusimano RJ, Panos A, Slutsky AS. Warm heart surgery. J Thorac Cardiovasc Surg 1991;101:269-74.

[2] Naylor CD, Lichtenstein SV, Fremes SE. Warm heart investigators. Randomised trial of normothermic versus hypothermic coronary bypass surgery. Lancet 1994;343:559-63.

[3] Cannon MB, Vine AJ, Kantor HL, et al. Warm and cold blood cardioplegia. Comparison of myocardial fuction and metabolism using ${ }^{31} \mathrm{P}$ magnetic resonance spectroscopy. Circulation 1994;90:328-38.

[4] Buckberg GD. Update on current techniques of myocardial protection. Ann Thorac Surg 1995;60:805-14.
[5] Mauney MC, Kron IL. The physiologic basis of warm cardioplegia. Ann Thorac Surg 1995;60:819-23.

[6] Calafiore AM, Teodori G, Bosco G, et al. Intermittent antegrade warm blood cardioplegia in aortic valve replacement. J Cardiovasc Surg 1996;11:348-54.

[7] Jacquet LM, Noirhomme PH, Van Dyck MJ, et al. Randomised trial of intermittent antegrade warm blood versus cold crystalloid cardioplegia. Ann Thorac Surg 1999;67:471-7.

[8] Shanewise JS, Kosinski AS, Coto JA, Jones EL. Prospective randomised trial comparing blood and oxygenated crystalloid cardioplegia in preoperative coronary artery bypass grafting. J Thorac Cardiovasc Surg 1998;115:1166-71.

[9] Hendrikx M, Jiang H, Gutermann H, et al. Release of cardiac troponin I in antegrade crystalloid versus blood cardioplegia. J Thorac Cardiovasc Surg 1999;118:452-9.

[10] Chambers DJ, Haire K, Morley N, et al. St. Thomas' Hospital cardioplegia: enhanced protection with exogenous creatine phosphate. Ann Thorac Surg 1996;61:67-75.

[11] Vinten-Johansen J, Julian JS, Yokoyama H, et al. Efficacy of myocardial protection with hypothermic blood cardioplegia depends on oxygen. Ann Thorac Surg 1991;52:939-48.

[12] Calafiore AM, Teodori G, Mezzetti A, et al. Intermittent antegrade warm blood cardioplegia. Ann Thorac Surg 1995;59: $398-402$.

[13] Holmvang L, Jurlander B, Rasmussen C, Thiis JJ, Grande P, Clemmensen P. Use of biochemical markers of infarction for diagnosing perioperative myocardial infarction and early graft occlusion after coronary artery bypass surgery. Chest 2002;121: $103-11$.

[14] Svedjeholm R, Dahlin LG, Lundberg C, et al. Are electrocardiographic Q-wave criteria reliable for diagnosis of perioperative myocardial infarction after coronary surgery? Eur J Cardiothorac Surg 1998;13:655-61.

[15] Matthews JNS, Altman DG, Cambell MJ, Royston P. Analysis of serial measurements in medical research. BMJ 1990;300:230-5.

[16] Krukenkamp IB. Cold and warm blood cardioplegia. Scand J Thorac Cardiovasc Surg, Suppl 1993;41:45-53.

[17] Giuliani I, Bertinchant JP, Granier C, et al. Determination of cardiac troponin I forms in the blood of patients with acute myocardial infarction and patients receiving crystalloid or cold blood cardioplegia. Clin Chem 1999;45:213-22.

[18] Magovern GJ, Flaherty JT, Gott VL, Bulkley BH, Gardner TJ. In vitro comparison of oxygen availability from asanguineous and sanguineous cardioplegic media. Circulation 1981;64:60-7.

[19] Digerness SB, Vanini V, Wideman FE. In vitro comparison of oxygen availability from asanguineous and sanguineous cardioplegic media. Circulation 1981;64(Suppl 2):80-3.

[20] Kaijeser L, Jansson E, Schmivt W, Bonfin V. Myocardial energy depletion during profound hypothermic cardioplegia for cardiac operation. J Thorac Cariovasc Surg 1985;80:896-900.

[21] Yau TM, Weisel RD, Mickle DAG, et al. Optimal delivery of blood cardioplegia. Circulation 1991;84(Suppl 3):380-8.

[22] Mezzetti A, Calafiore AM, Lapenna D, et al. Intermittent antegrade warm cardioplegia reduces oxidative stress and improves metabolism of the ischemic-reperfused human myocardium. J Thorac Cardiovasc Surg 1995; 109:787-95.

[23] Brown WM, Jay JL, Gott JP, et al. Warm blood cardioplegia: superior protection after acute myocardial ischemia. Ann Thorac Surg 1993;55:32-42.

[24] Lichtenstein SV, el Dalati H, Panos A, Slutsky AS. Long cross-clamp times with warm heart surgery. Lancet 1989;1(8652):1443.

[25] Caputo M, Ascione R, Angelini GD, Suleiman MS, Bryan AJ. The end of the cold era: from intermittent cold to intermittent warm blood cardioplegia. Eur J Cardiovasc Sur 1998;14:467-75.

[26] Tian G, Shen J, Su S, et al. Assessement of retrograde cardioplegia with magnetic resonance imaging and localized ${ }^{31} \mathrm{P}$ spectroscopy in isolated pig hearts. J Thorac Cardiovasc Surg 1997;114:109-16. 